Vol. 96, N 0.3 September 2002

\section{Notes from the Editor}

The first thing most readers will notice about this issue is the cover, which is colored blue this time and is adorned by a clock to signify "Taking Temporality Seriously," the first article in the issue. A fter noting the cover (admiringly, I hope) and browsing through the table of contents, readers are hereby invited to shift their attention briefly to the roster of editorial board members inside the cover. There they will see something new: as previewed in an earlier "N otes from the Editor," an executive committee of the Review's editorial board is now in operation. The six-member executive committee consists of four representatives of major subfields of the discipline ( $D$ arren $D$ avis for A merican politics, J ames M orrow for international politics, Kirstie McClure for political theory, and Sven Steinmo for comparative politics) and two "at-large" members (N eta Crawford and R obert Goodin). The members of the executive committee are intended to be the "first among equals" in advising me on matters of editorial policy, serving as an initial sounding board and source of new ideas before issues come to the full editorial board. Pertinent examples of the committee's responsibilities include planning an appropriate commemoration of the Review's centenary and revisiting our procedures for handling "Forum" submissions and responses. Executive committee members also constitute a first line of defense in advising me when issues arise concerning particular manuscripts, though such responsibilities tend to be infrequent and, given the diversity of the manuscripts we consider, are fairly widely dispersed among members of the editorial board rather than confined solely to executive committee members. A II editorial board members also share responsibility for "recruiting" promising manuscripts within their areas of expertise, but executive committee members are asked to be especially active in this regard. Finally, it is the executive committee that will, early in 2003 , review the performance of our editorial office in general and my performance as editor in particular. With the latter point in mind, I want to emphasize (1) that I selected the executive committee with an eye toward diversity of various sorts (substantive, theoretical, methodological, demographic, and so on), and (2) that the executive committee consists of individuals with whom I have not been associated professionally or personally, apart from my familiarity with their work, and with whom I have no more than a nodding acquaintance, if that.

Let me also take this occasion to alert or remind readers that the $D$ ecember issue of the R eview will be the last one in which book reviews appear. The book review operation, under the continuing editorship of Susan Bickford and G regory M cA voy, is shifting over to the A PSA 's new journal, Perspectives on Politics, the first issue of which is scheduled to appear during the first quarter of 2003. Jennifer $\mathrm{H}$ ochschild, the editor of Perspectives on Politics, has announced ambitious plans for a journal that will, in her words, "enable members of different subfields of political science to speak to one another-and with knowledgeable people outside the discipline- on issues of common interest."

of course, that is a worthy aspiration for the Review as well, notwithstanding differences between its mission and that of the new journal. Besides book reviews, Perspectives on Politics will feature review essays, research articles that are more broadly focused than standard reports of individual research results, and "intervention" essays (brief commentaries on some political phenomenon or problem, exchanges about substantive or methodological issues, and introductions to or assessments of new ideas and trends). The advent of the new journal is an exciting development for our discipline, and I look forward to its appearance early next year.

\section{IN THIS ISSUE}

In this issue's first article, Tim B üthe takes political scientists to task for their inattention to the historical dimension. The proper role of history in political analysis has been a source of heated debate, and oceans of ink have been spilled in attempts to determine where and how history "fits." Going beyond this debate in "Taking Temporality Seriously: M odeling $\mathrm{H}$ istory and the $U$ se of Narratives as Evidence," Büthe suggests ways to improve models by incorporating historical narratives. This exploration of the use and abuse of historical analysis by political scientists, though unlikely to settle major issues with finality, impressed our reviewers as having the potential to direct the ongoing debate in productive new directions.

A Iso likely to spur controversy is A rash A bizadeh's "Does Liberal Democracy Presuppose a Cultural $\mathrm{N}$ ation? Four A rguments." In this essay, A bizadeh challenges the idea that liberal democracy is viable only within the context of a single cultural nation. D rawing from diverse approaches to political theory, he contends that the identity derived from a cultural nation (defined in linguistic-cultural terms) may undermine democratic principles and may fail to take into account multinational and post-national contexts. By systematically reconsidering widely accepted ideas about cultural requisites, this analysis should constitute a fine starting point for creating a broader normative theory of liberal democracy.

In contrast to many political scientists who study the A merican judicial system, Howard Gillman perceives the courts as enmeshed within party regimes rather than as an outside force constraining or balancing political parties. In "H ow Political Parties Can $\mathrm{U}$ se the Courts to A dvance Their A gendas: Federal Courts in the U nited States, 1875-1891," Gillman details the changing and expanding role of the federal courts in advancing the long-term R epublican goal of altering A merica's economic foundations. In a study whose implications extend far beyond the courts and 
the U.S., G illman addresses key issues of constitutionalism, institutionalization, and political development.

Whereas G illman focuses specifically on a particular period and place, the question of "W hat is virtue?" knows no temporal or spatial boundaries. This question is at the center of a lively and often heated debate among contemporary political theorists. However, as R obert Bartlett argues in "Socratic Political Philosophy and the Problem of Virtue," the responses that have been offered to date are problematic. Virtue, he contends, cannot be reduced to a dichotomy between public and private good, individual and community, duty and happiness. B ased on his intensive exegesis of Plato's M eno, B artlett suggests that including nobility in the definition of virtue will bridge the dichotomies of previous scholarship.

Two contributions to this issue focus on gender politics. In the first, Eileen M CD onagh tries to explain how women win the rights to vote and hold office and how much representation they gain in national legislatures. In "Political Citizenship and Democratization: The G ender Paradox," M CD onagh challenges conventional wisdom by arguing that liberal principles that protect individual rights, such as suffrage and equality, do not explain the extension of political rights to women. A nalyzing the constitutions of 190 countries and presenting an in-depth case study of the process through which women won suffrage in the $U$ nited States, M cD onagh shows that national differences in extending greater rights to women reflect the extent to which constitutions embrace both group and individual rights. Paradoxically, the political inclusion of women stems from a dual emphasis on what defines them as a group (i.e., their difference from men) and their status as individuals who deserve the same rights as all other individuals.

In "Lipstick and Logarithms: Gender, Identity, Institutional Context, and Representative Bureaucracy," L ael K eiser, Vicky Wilkins, K enneth M eier, and Catherine $\mathrm{H}$ olland shift from M CD onagh's focus on the "descriptive" representation of women to the next logical question: D oes "descriptive" or "passive" representation lead to "substantive" or "active" representation? E vidence of gains for racial minorities through passive representation has been abundantly documented, but gains for women are not well documented. A s a test case, $\mathrm{K}$ eiser and her colleagues ask whether female students in schools with more women math teachers perform better on standardized math tests. Their analysis brings new data to bear on an issue that has important policy implications, while speaking to an array of issues in feminist, democratic, and neoinstitutionalist theories.

In "Self-Interest, Social Security, and the Distinctive Participation Patterns of Senior Citizens," A ndrea L ouise Campbell's point of departure is the well known positive correlation between personal income and political participation in the U nited States. A Ithough that relationship is well established, Campbell uncovers an intriguing exception: It reverses for senior citizens when Social Security comes into play. Social Security occupies a unique status as a government policy that the poor depend on more than the rich, but also as one to which no "welfare" stigma is attached because it is considered earned. Thus, Social Security mobilizes the elderly segment of the poor population to act politically in their own self-interest in a way unmatched by other economic policies. This study will have to be taken into account in future analyses of the socioeconomic bases of mass political behavior and of the role of self-interest in shaping political attitudes.

A simple account of the timing of elections in parliamentary systems rests on the idea that officeholders behave strategically, calling new elections when they think their party's prospects are brighter than they are likely to be in the future. In "Strategic Parliamentary D issolution," however, K aare Strøm and Stephen Swindle contend that the matter is not nearly that simple, for the conventional account ignores institutional arrangements imposed on leaders by their countries' constitutions. By cataloguing the diverse set of pertinent constitutional provisions, constructing and solving games in which payoffs to the incumbents are based on these provisions, and using data on 192 elections in 18 parliamentary democracies to test hypotheses derived from these games, Strøm and Swindle greatly enrich our understanding of this familiar parliamentary tactic. M ore broadly, they provide superb demonstrations of the impact of institutional arrangements and of the fruitful interplay between formal theory and empirical testing.

Finally, in "Commerce, Coalitions, and Factor M obility: Evidence from Congressional Votes on Trade L egislation," M ichael H iscox notes that at some points in U.S. history, conflict over international trade has centered on broad class divisions. A t other times, though, the conflict has been between narrower and more fluid coalitions of industries. Hiscox invokes factor mobility - "the ease with which owners of factors of production (land, labor, and capital) can move between industries" - to identify the points at which an industrybased coalitions model has been a better predictor of congressional voting on international trade issues than a class-based model. $\mathrm{H}$ is analysis helps us understand the divisiveness of tariff and trade issues, and has direct implications for pluralist and $M$ arxist models of political conflict.

\section{INSTRUCTIONS TO CONTRIBUTORS}

\section{General Considerations}

The APSR strives to publish scholarly research of exceptional merit, focusing on important issues and demonstrating the highest standards of excellence in conceptualization, exposition, methodology, and craftsmanship. Because the APSR reaches a diverse audience of scholars and practitioners, authors must demonstrate how their analysisilluminates a significant research problem, or answers an important research question, of general interest in political science. For the same reason, authors must strive for a presentation that 
will be understandable to as many scholars as possible, consistent with the nature of their material.

The APSR publishes original work. Therefore, authors should not submit articles containing tables, figures, or substantial amounts of text that have al ready been published or are forthcoming in other places, or that have been included in other manuscripts submitted for review to book publishers or periodicals (including on-line journals). In many such cases, subsequent publication of this material would violate the copyright of the other publisher. The A PSR also does not consider papers that are currently under review by other journals or duplicate or overlap with parts of larger manuscripts that have been submitted to other publishers (including publishers of both books and periodicals). Submission of manuscripts substantially similar to those submitted or published elsewhere, or to part of a book or other larger work, is also strongly discouraged. If you have any questions about whether these policies apply in your particular case, you should discuss any such publications related to a submission in a cover letter to the E ditor. Y ou should also notify the E ditor of any related submissions to other publishers, whether for book or periodical publication, that occur while a manuscript is under review by the A PSR and which would fall within the scope of this policy. The $E$ ditor may request copies of related publications.

If your manuscript contains quantitative evidence and analysis, you should describe your procedures in sufficient detail to permit reviewers to understand and evaluate what has been done and, in the event that the article is accepted for publication, to permit other scholars to carry out similar analyses on other data sets. For example, for surveys, at the least, sampling procedures, response rates, and question wordings should be given; you should calculate response rates according to one of the standard formulas given by the A merican A ssociation for Public O pinion R esearch, Standard D efinitions: F inal D ispositions of C ase Codes and Outcome Rates for RDD Telephone Surveys and In-Person Household Surveys (A nn A rbor, M I: A A POR, 1998). This document is available on the Internet at <http://www.aapor.org/ethics/stddef.html>. For experiments, provide full descriptions of experimental protocols, methods of subject recruitment and selection, subject payments and debriefing procedures, and so on. A rticles should be self-contained, so you should not simply refer readers to other publications for descriptions of these basic research procedures.

Please indicate variables included in statistical analyses by capitalizing the first letter in the variable name and italicizing the entire variable name the first time each is mentioned in the text. You should also use the same names for variables in text and tables and, wherever possible, should avoid the use of acronyms and computer abbreviations when discussing variables in the text. A II variables appearing in tables should have been mentioned in the text and the reason for their inclusion discussed.

A s part of the review process, you may be asked to submit additional documentation if procedures are not sufficiently clear; the review process works most efficiently if such information is given in the initial submission. If you advise readers that additional information is available, you should submit printed copies of that information with the manuscript. If the amount of this supplementary information is extensive, please inquire about alternate procedures.

The A PSR uses a double-blind review process. Y ou should follow the guidelines for preparing anonymous copies in the Specific Procedures section below.

$M$ anuscripts that are largely or entirely critiques or commentaries on previously published A PSR articles will be reviewed using the same general procedures as for other manuscripts, with one exception. In addition to the usual number of reviewers, such manuscripts will also be sent to the scholar(s) whose work is being criticized, in the same anonymous form that they are sent to reviewers. Comments from the original author(s) to the $E$ ditor will be invited as a supplement to the advice of reviewers. This notice to the original author(s) is intended (1) to encourage review of the details of analyses or research procedures that might escape the notice of disinterested reviewers; (2) to enable prompt publication of critiques by supplying criticized authors with early notice of their existence and, therefore, more adequate time to reply; and (3) as a courtesy to criticized authors. If you submit such a manuscript, you should therefore send as many additional copies of their manuscripts as will be required for this purpose.

$M$ anuscripts being submitted for publication should be sent to Lee Sigelman, Editor, A merican Political Science Review, Department of Political Science, The George Washington U niversity, 2201 G Street N.W., R oom 507, Washington, DC 20052. Correspondence concerning manuscripts under review may be sent to the same address or e-mailed to apsr@gwu.edu.

\section{Manuscript Formatting}

$M$ anuscripts should not be longer than 45 pages including text, all tables and figures, notes, references, and appendices. This page size guideline is based on the U.S. standard $8.5 \times 11$-inch paper; if you are submitting a manuscript printed on longer paper, you must adjust accordingly. The font size must be at least 11 points for all parts of the paper, including notes and references. The entire paper, including notes and references, must be double-spaced, with the sole exception of tables for which double-spacing would require a second page otherwise not needed. A II pages should be numbered in one sequence, and text should be formatted using a normal single column no wider than 6.5 inches, as is typical for manuscripts (rather than the double-column format of the published version of the A PSR ), and printed on one side of the page only. Include an abstract of no more than 150 words. The APSR style of embedded citations should be used, and there must be a separate list of references at the end of the manuscript. D o not use notes for simple citations. These specifications are designed to make it easier for reviewers to read and evaluate papers. Papers not adhering to these guidelines are subject to being rejected without review. 
For submission and review purposes, you may place footnotes at the bottom of the pages instead of using endnotes, and you may locate tables and figures (on separate pages and only one to a page) approximately where they fall in the text. However, manuscripts accepted for publication must be submitted with endnotes, and with tables and figures on separate pages at the back of the manuscript with standard indications of text placement, e.g., [Table 3 about here]. In deciding how to format your initial submission, please consider the necessity of making these changes if your paper is accepted. If your paper is accepted for publication, you will also be required to submit camera-ready copy of graphs or other types of figures. Instructions will be provided.

For specific formatting style of citations and references, please refer to articles in the most recent issue of the APSR. For unusual style or formatting issues, you should consult the latest edition of The Chicago $M$ anual of Style. For review purposes, citations and references need not be in specific A PSR format, although some generally accepted format should be used, and all citation and reference information should be provided.

\section{Specific Procedures}

Please follow these specific procedures for submission:

1. You are invited to submit a list of scholars who would be appropriate reviewers of your manuscript. The Editor will refer to this list in selecting reviewers, though there obviously can be no guarantee that those you suggest will actually be chosen. Do not list anyone who has already commented on your paper or an earlier version of it, or any of your current or recent collaborators, institutional colleagues, mentors, students, or close friends.

2. Submit five copies of manuscripts and a diskette containing the word-processed version of the manuscript. Please ensure that the paper and diskette versions you submit are identical; the diskette version should be of the anonymous copy (see below). Please review all pages of all copies to make sure that all copies contain all tables, figures, appendices, and bibliography mentioned in the manuscript and that all pages are legible. $\mathrm{L}$ abel the diskette clearly with the (first) author's name and the title of the manuscript (in abridged form if need be), and identify the word processing program and operating system.

3. To comply with the A PSR's procedure of doubleblind peer reviews, only one of the five copies submitted should be fully identified as to authorship and four should be in anonymous format.

4. For anonymous copies, if it is important to the development of the paper that your previous publications be cited, please do this in a way that does not make the authorship of the submitted paper obvious. This is usually most easily accomplished by referring to yourself in the third person and including normal references to the work cited in the list of references. In no circumstances should your prior publications be included in the bibliography in their normal al phabetical location but with your name deleted. A ssuming that text references to your previous work are in the third person, you should include full citations as usual in the bibliography. Please discuss the use of other procedures to render manuscripts anonymous with the E ditor prior to submission. You should not thank colleagues in notes or elsewhere in the body of the paper or mention institution names, web page addresses, or other potentially identifying information. A Il acknowledgments must appear on the title page of the identified copy only. M anuscripts that are judged not anonymous will not be reviewed.

5. The first page of the four anonymous copies should contain only the title and an abstract of no more than 150 words. The first page of the identified copy should contain (a) the name, academic rank, institutional affiliation, and contact information (mailing address, telephone, fax, e-mail address) for all authors; (b) in the case of multiple authors, an indication of the author who will receive correspondence; (c) any relevant citations to your previous work that have been omitted from the anonymous copies; and (d) acknowledgments, including the names of anyone who has provided comments on the manuscript. If the identified copy contains any unique references or is worded differently in any way, please mark this copy with "Contains author citations" at the top of the first page.

N o copies of submitted manuscripts can be returned.

\section{ELECTRONIC ACCESS TO THE APSR}

Back issues of the APSR are available in several electronic formats and through several vendors. Except for the last three years (as an annually "moving wall"), back issues of the APSR beginning with Volume 1, Number 1 (November 1906), are available on-line through J ST O R (http://wwwjstor.org/) . A t present, J ST OR 's complete journal collection is available only via institutional subscription, e.g., through many college and university libraries. For A PSA members who do not have access to an institutional subscription to JSTOR, individual subscriptions to its APSR content are available. Please contact M ember Services at A PSA for further information, including annual subscription fees.

Individual members of the A merican Political Science $A$ ssociation can access recent issues of the A PSR and PS through the A PSA website (www.apsanet.org) with their username and password. Individual nonmember access to the online edition will also be available, but only through institutions that hold either a print-plus-electronic subscription or an electronic-only subscription, provided the institution has registered and activated its online subscription.

Full text access to current issues of both the APSR and PS is also available on-line by library subscription 
Vol. 96, N 0.3

from a number of database vendors. Currently, these include U niversity M icrofilms Inc. (U MI) (via its CD ROM s G eneral Periodicals O nline and Social Science Index and the on-line database ProQ uest D irect), 0 nline Computer Library Center (OCLC) (through its on-line database First Search as well as on CD -R OM s and magnetic tape), and the Information A ccess Company (IAC) (through its products Expanded A cademic Index, InfoTrac, and several on-line services [see below]). O thers may be added from time to time.

The APSR is also available on databases through six online services: $D$ atastar ( $D$ atastar), B usiness Library (D ow Jones), Cognito (IAC), E ncarta O nline Library (IA C), IA C B usiness (D ialog), and N ewsearch (Dialog).

The editorial office of the A PSR is not involved in the subscription process to either JSTOR for back issues or the other vendors for current issues. Please contact A PSA, your referencelibrarian, or the database vendor for further information about availability.

\section{BOOK REVIEWS}

A Il books for review should be sent directly to the A PSR Book Review Editors, Susan Bickford and $G$ reg M cA voy. The address is Susan Bickford and G regory M cA voy, A merican Political Science Review Book R eview Editors, Department of Political Science, U niversity of North Carolina at Chapel $\mathrm{Hill}$, CB No. 3265, Chapel Hill, NC 27599-3265. E-mail: apsrbook@unc.edu.

If you are the author of a book you wish to be considered for review, please ask your publisher to send a copy to the A PSR B ook R eview E ditors per the mailing instructions above. If you are interested in reviewing books for the A PSR, please send your vita to the B ook R eview E ditors; you should not ask to review a specific book.

\section{OTHER CORRESPONDENCE}

The A merican Political Science A ssociation's address, telephone, and fax are $1527 \mathrm{~N} \mathrm{ew} \mathrm{H}$ ampshire A venue, N.W., Washington, D.C. 20036, (202) 483-2512 (voice), and (202) 483-2657 (fax). E-mail: apsa@apsanet.org. Please direct correspondence as follows.

Information, including news and notes, for PS:

D r. R obert J -P. H auck, E ditor, PS

E-mail: rhauck@apsanet.org

Circulation and subscription correspondence (domestic claims for nonreceipt of issues must be made within four months of the month of publication; overseas claims, within eight months):

E lizabeth Weaver E ngel,

D irector of $M$ ember Services

E-mail: membership@apsanet.org

Reprint permissions:

E-mail: reprints@apsanet.org
A dvertising information and rates:

A dvertising Coordinator, Cambridge U niversity Press

E-mail: journals_advertising@cup.org

\section{EXPEDITING REQUESTS FOR COPYING APSR AND PS ARTICLES FOR CLASS USE AND OTHER PURPOSES}

\section{Class Use}

The Comprehensive Publisher Photocopy A greement between A PSA and the Copyright Clearance Center (CCC) permits bookstores and copy centers to receive expedited clearance to copy articles from the A PSR and PS in compliance with the A ssociation's policies and applicable fees. The general fee for articles is 75 cents per copy. H owever, current A ssociation policy levies no fee for the first 10 copies of a printed artide, whether in course packs or on reserve. Smaller classes that rely heavily on articles (i.e., upper-level undergraduate and graduate classes) can take advantage of this provision, and faculty ordering 10 or fewer course packs should bring it to the attention of course pack providers. A PSA policy also permits free use of the electronic library reserve, with no limit on the number of students who can access the electronic reserve. B oth large and small classes that rely on these articles can take advantage of this provision. The CCC's address, telephone, and fax are 222 Rosewood Drive, Danvers, M A 01923, (978) 750-8400 (voice), and (978) 750-4474 (fax). This agreement pertains only to the reproduction and distribution of A PSA materials as hard copies (e.g., photocopies, microfilm, and microfiche).

The A ssociation of A merican Publishers (AAP) has created a standardized form for college faculty to submit to a copy center or bookstore to request copyrighted material for course packs. The form is available through the CCC, which will handle copyright permissions.

A PSA also has a separate agreement pertaining to CCC's A cademic E-R eserve Service. This agreement allows electronic access for students and instructors of a designated class at a designated institution for a specified article or set of articles in electronic format. A ccess is by password for the duration of a class.

Please contact your librarian, the C C C, or the A PSA $R$ eprints $D$ epartment for further information.

\section{APSR Authors}

If you are the author of an A PSR article, you may use your article in course packs or other printed materials without payment of royalty fees and you may post it at personal or institutional web sites as long as the A PSA copyright notice is included.

\section{Other Uses of APSA-Copyrighted Materials}

For any further copyright issues, please contact the A PSA R eprints D epartment. 


\section{INDEXING}

A rticles appearing in the A PSR before J une 1953 were indexed in The R eader's $G$ uide to Periodical $L$ iterature. Current issues are indexed in A BC Pol Sci; A merica, $\mathrm{H}$ istory and L ife 1954-; B ook R eview Index; Current Contents: Social and Behavioral Sciences; EconLit; Energy Information Abstracts; Environmental A bstracts; Historical A bstracts; Index of Economic A rticles; Information Service Bulletin; International Index; International Political Science A bstracts; the Journal of E conomic L iterature; Periodical A bstracts;
Public A ffairs; R ecently Published A rticles; R eference Sources; Social Sciences and Humanities Index; Social Sciences Index; Social Work Research and A bstracts; and W ritings on A merican History. Some of these sources may be available in electronic form through local public or educational libraries. M icrofilm of the A PSR, beginning with Volume 1 , and the index of the A PSR through 1969 are available through U niversity M icrofilms Inc., $300 \mathrm{~N}$ orth Z eeb R oad, A nn A rbor, MI 48106 (www.umi.com). The Cumulative Index to the A merican Political Science R eview, Volumes 63 to 89: 1969-95, is available through the A PSA . 